\title{
Estimating the economic impact of the 2014 Ebola virus outbreak in West Africa: an empirical approach
}

\author{
Mohamed Jalloh \\ Economic Policy Analysis Unit (EPAU), \\ Macroeconomic Policy Department, \\ ECOWAS Commission, \\ River Plaza, Central Area, Abuja, Nigeria \\ Email: medjal99@yahoo.com
}

\begin{abstract}
The 2014 Ebola outbreak in West Africa is one of the most devastating in history. The devastating nature of this epidemic drew worldwide attention as it spread across borders. This study therefore, aimed at evaluating the economic impact of the epidemic in countries affected. The study adopted an innovative methodology that captures the contemporaneous impact of the outbreak on key economic variables of interest. The results from the study revealed that in addition to the adverse impact of the Ebola disease, the isolation of countries affected by the epidemic contributed immensely in worsening their economic conditions. Thus, the study noted the need for strengthening healthcare systems, enhancing the capacity of health workers, non-restriction on the movement of persons and goods and the need for regional coordination of efforts in combating epidemic outbreaks in the future.
\end{abstract}

Keywords: Ebola; outbreak; economic; epidemic; devastating; West Africa; combating.

Reference to this paper should be made as follows: Jalloh, M. (2019) 'Estimating the economic impact of the 2014 Ebola virus outbreak in West Africa: an empirical approach', Int. J. Healthcare Policy, Vol. 1, No. 1, pp.1-23.

Biographical notes: Mohamed Jalloh holds a $\mathrm{PhD}$ in Economics from the University of Ibadan in Nigeria as well as a Doctorate degree in Business Administration (DBA) from the USA. He is currently a Principal Researcher in the Economic Policy Analysis Unit (EPAU), Macroeconomic Policy Department of the ECOWAS Commission in Abuja, Nigeria. He was a Lecturer at the University of Sierra Leone as well as the first Director General of the Sierra Leone Stock Exchange. He is a network member of the African Economic Research Consortium (AERC) based in Nairobi, Kenya and also the Society for the Study of Emerging Markets. He was also a Visiting Scholar at the International Monetary Fund (IMF), Washington DC in USA.

\section{Introduction}

The 2014 Ebola outbreak in West Africa has been widely acknowledged as one of the most devastating Ebola outbreaks in history and the first ever witnessed in West Africa. As of end August 2014, an update from the World Health Organization (WHO) indicates that a total of 3,685 cases of Ebola virus infections have been confirmed including 
1,841 deaths from the four West African States of Guinea, Liberia and Nigeria and Sierra Leone. What is more scaring is that a high proportion of those infected by the Ebola outbreak in West Africa included health workers who are even grossly inadequate to handle the increasing number of cases across the affected countries. The acute shortage of protective equipment as well as their improper use amounted to the high death toll amongst health workers, particularly doctors and nurses. WHO also reported that as of end August 2014, more than 240 healthcare workers have developed the Ebola virus disease in Guinea, Liberia, Nigeria, and Sierra Leone, and more than 120 eventually died (i.e., $50 \%$ death rate). The high risk of contracting the disease amongst health workers coupled with their deplorable conditions of service resulted to the frequent occurrence of strikes amongst health workers demanding for better conditions of services in countries hardest hit by the Ebola outbreak. According to the WHO, in the three Ebola hardest-hit countries of Guinea, Liberia and Sierra Leone, only one to two doctors are available to treat 100,000 people, and that these doctors are mostly concentrated in urban areas. This situation created the stage for the disease to rapidly spread to the capital cities of the three countries as people affected by the virus seek for medical attention in cities where they can lay hands on the few available doctors.

As the gravity of the outbreak continued to unleash its devastating impact in West Africa, the Economic Community of West African States (ECOWAS) became increasing worried about the future of the sub-region which has been performing extremely well in terms of maintaining the momentum for boosting economic growth in member states. In 2013, the West African region recorded the highest growth rate of $6.3 \%$ of real GDP when compared to all other Regional Economic Communities (RECs) in Africa. Output growth in West Africa was expected to remain quite robust and was projected at around $6.9 \%$ in 2014. The expected rise in production in 2014 was in relation to the consolidation of fundamental factors of regional growth, particularly the demand for minerals and hydrocarbons, as well as the good performance of agricultural production. Indeed according to the 2014 projections, real GDP growth of Nigeria, Africa's highest oil producer, will progress to $7.4 \%$ against $6.9 \%$ in 2013 . Growth consolidation in Côte d'Ivoire (9.1\%) and robust activity in Ghana $(6.1 \%)$ are equally explanatory factors. Furthermore, the projections revealed the region's encouraging performances with 11 countries that will achieve in 2014 growth rates of at least $7.0 \%$. Among these countries, Burkina (7\%), Côte d'Ivoire (9.1\%), Ghana (8.0), Gambia $(8.5 \%)$, Niger $(8.2 \%)$, Nigeria $(7.4 \%)$ and Sierra Leone $(14 \%)$ will record growth rates higher than $7 \%$.

On account of the increasingly devastating effects of the Ebola virus outbreak, mining activities in Sierra Leone recorded a significantly declining trend, resulting in the reversal of projections for 2014 economic growth rate from $11.3 \%$ to $7.1 \%$. For Liberia and Guinea, the World Bank revised its projections for 2014 economic growth rates from $5.9 \%$ and $4.5 \%$ to $2.5 \%$ and $2.4 \%$ respectively. In all the three hardest hit countries, whilst fiscal revenues are declining, government spending has significantly increased in trying to contain the spread of the disease. This resulted in a widening of fiscal deficits in these countries. This development amounted to raising some level of skepticism as to whether the region's good growth prospects will be maintained as projected earlier by the World Bank. In view of this ugly development, the general objective of this study, 
therefore, aims at evaluating the economic impact of the 2014 Ebola outbreak in West Africa, most particularly those hardest hit by the outbreak. The specific objectives are to assess the relative effects of the 2014 Ebola outbreak on economic growth, commodity prices (COMPR) and the fiscal deficits of those countries affected by the outbreak.

Following the introductory section, the remaining part of this paper is organised as follows. Section 2 provides an over view of the 2014 Ebola virus outbreak in West Africa. In Section 3, the study provides a review of the relevant literature on Ebola virus outbreaks. In Section 4, the study develops an innovative methodology that will best capture the relative effects of the Ebola outbreak on the economies of the countries affected by the epidemic. Whilst Section 5 presents and interprets the estimation results, Section 6 concludes and proffers some policy recommendations based on the findings of the study.

\section{Overview of the 2014 Ebola outbreak in West Africa}

'The serious stage of the 2014 Ebola outbreak in West Africa started since the beginning of June 2014 when the Ebola epidemic started' drawing international attention owing to the increasing rate at which the disease spread across borders as well as its rising death toll. By 16th June 2014, the cumulative number of reported cases of the Ebola virus disease in Guinea surged to 398, including 264 deaths. The corresponding figures for Sierra Leone during the same period were 97 cases and 49 deaths. As of 30 June 2014, the cumulative number of cases attributed to the Ebola virus infection in the three countries stood at 759, including 467 deaths. The distribution of these cases and deaths are as follows: Guinea, 413 cases and 303 deaths; Liberia, 107 cases and 65 deaths; and Sierra Leone, 239 cases and 99 deaths. Table 1 shows the distribution of cases and deaths from the Ebola virus in the three West African countries of Guinea, Liberia and Sierra Leone.

Figure 1 Cumulative totals of Ebola virus cases (June to July 2014) (see online version for colours)

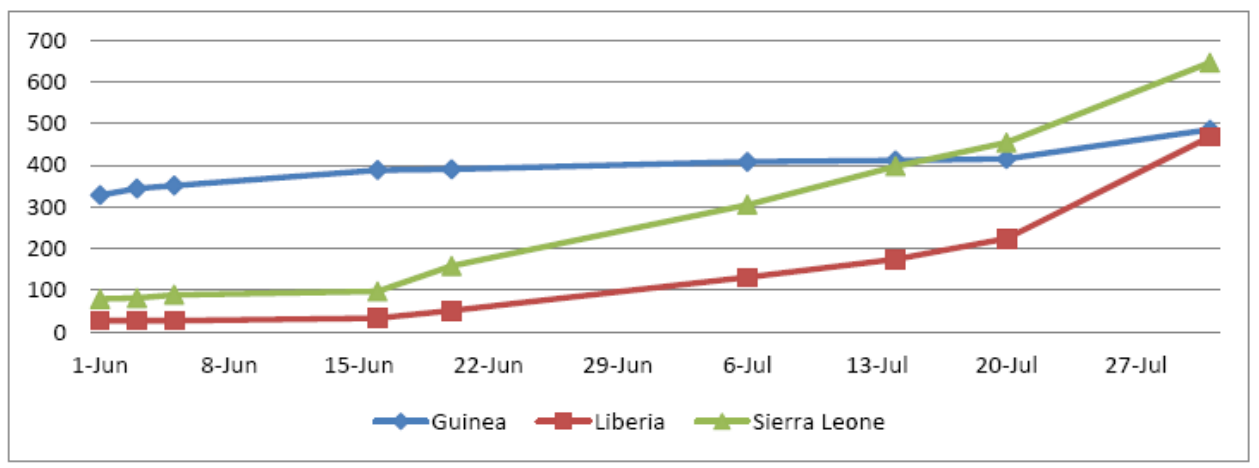

Source: WHO updates on Ebola outbreak in West Africa 
Table 1 Infection cases and deaths from the Ebola virus disease (June to July 2014)

\begin{tabular}{|c|c|c|c|c|c|c|}
\hline \multirow{2}{*}{ Date } & \multicolumn{3}{|c|}{ Guinea } & \multicolumn{3}{|c|}{ Liberia } \\
\hline & Cases & Deaths & $C F R$ & Cases & Deaths & $C F R$ \\
\hline 1st June & 328 & 208 & $63.4 \%$ & 27 & 13 & $48.1 \%$ \\
\hline 3 June & 344 & 215 & $62.5 \%$ & 27 & 13 & $48.1 \%$ \\
\hline 5 June & 351 & 226 & $64.4 \%$ & 27 & 13 & $48.1 \%$ \\
\hline 16 June & 398 & 264 & $66.3 \%$ & 33 & 24 & $72.7 \%$ \\
\hline 20 June & 390 & 270 & $69.2 \%$ & 51 & 34 & $66.7 \%$ \\
\hline 6 July & 408 & 307 & $75.2 \%$ & 131 & 84 & $64.1 \%$ \\
\hline 14 July & 411 & 310 & $75.4 \%$ & 174 & 106 & $60.9 \%$ \\
\hline 20 July & 415 & 314 & $75.5 \%$ & 224 & 127 & $56.7 \%$ \\
\hline 31 July & 485 & 358 & $78.8 \%$ & 468 & 255 & $54.5 \%$ \\
\hline \multirow{2}{*}{ Date } & \multicolumn{3}{|c|}{ Sierra Leone } & \multicolumn{3}{|c|}{ Cumulative totals } \\
\hline & Cases & Deaths & $C F R$ & Cases & Deaths & $C F R$ \\
\hline 1st June & 79 & 6 & $7.6 \%$ & 434 & 227 & $52.3 \%$ \\
\hline 3 June & 81 & 6 & $7.4 \%$ & 452 & 234 & $51.7 \%$ \\
\hline 5 June & 89 & 7 & $7.9 \%$ & 467 & 246 & $52.7 \%$ \\
\hline 16 June & 97 & 49 & $50.5 \%$ & 528 & 337 & $63.8 \%$ \\
\hline 20 June & 158 & 53 & $33.5 \%$ & 599 & 357 & $59.6 \%$ \\
\hline 6 July & 305 & 127 & $41.6 \%$ & 844 & 518 & $61.4 \%$ \\
\hline 14 July & 397 & 197 & $49.6 \%$ & 982 & 613 & $62.4 \%$ \\
\hline 20 July & 454 & 219 & $48.2 \%$ & 1093 & 660 & $60.4 \%$ \\
\hline 31 July & 646 & 273 & $42.3 \%$ & 1599 & 886 & $54.4 \%$ \\
\hline
\end{tabular}

Source: WHO updates and author's calculation of case fatality rates (CFR)

The situation continued to worsen in the three countries of Guinea, Liberia and Sierra Leone. As of 6 July 2014, the cumulative number of cases attributed to the Ebola virus disease in the three countries stood at 844, including 518 deaths. The distribution of Ebola infection (EBOINF) cases and deaths were as follows: Guinea, 408 cases and 307 deaths, Liberia, 131 cases and 84 deaths; and Sierra Leone, 305 cases and 127 deaths.

From Figure 1, it can be inferred that the infection rate of the Ebola virus disease is accelerating. The catastrophic or out of control phase started manifesting itself when the outbreak became so widespread and deadly that the whole world started getting panicking. On 25 July 2014, the first case of the Ebola virus disease was transmitted to the most populous West African country of Nigeria. This immediately ignited drastic responses from other countries in West Africa and beyond through various radical measures that restricted the free movement of persons from the three hardest hit West African countries of Guinea, Liberia and Sierra Leone. These responses came in the form of cancelation of flights ${ }^{1}$ by airlines to the affected countries, land border ${ }^{2}$ closure by neighbouring West African countries, and even quarantining of certain regions within affected countries. ${ }^{3}$ 
Table 2 Infection cases and deaths from the Ebola virus disease (August 2014)

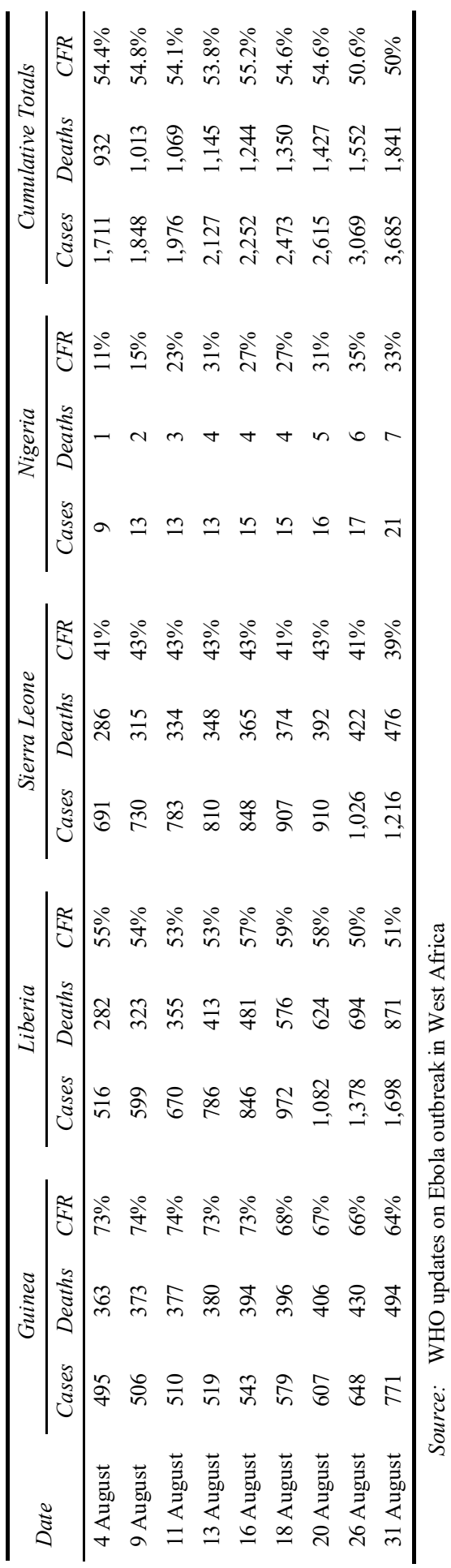


Consequently, the rate of infection of the Ebola virus garnered a new momentum during the month of August 2014, since affected countries were finding it increasingly difficult to contain the spread of the disease as importation of necessary equipment aiding the combating of the disease became difficult amidst the international isolation (ISOL). It also became increasingly difficult to fly in medical experts from other parts of the world to assist affected countries in containing the spread of the disease. Consequently, between 4 and 31 August 2014 the number of Ebola virus infection cases in the affected West African countries of Guinea, Liberia, Sierra Leone and Nigeria skyrocketed from 1,711 to 3,685 (an increases of $115.4 \%$ ). Death cases related to the virus infection rose from 932 to around 1841 (an increase of 97.5\%). During this period, whilst infection cases in Guinea, Liberia and Sierra Leone rose by $55.8 \%, 229.1 \%$ and $75.9 \%$, death-related cases arising from the disease went up by $36.1 \%, 208.8 \%$ and $66.4 \%$, respectively. For Nigeria, whilst the number of Ebola infected cases rose from 9 to 21, the number of death-related cases arising from the disease went up from 1 to 7 deaths.

From this breakdown, it can be inferred that the Ebola virus disease wrecked more havoc in Liberia during the month of August than any other country affected by the outbreak, A better understanding of the dynamics of the Ebola virus disease infection amongst the affected countries of Guinea, Liberia Nigeria and Sierra Leone during the month of August could be appreciated as presented in Figure 2. As shown in Figure 2, it could be observed that since the beginning of August 2014 Liberia (in red colour) has been recording more and more cases of Ebola virus infections. As of 31 August, Liberia alone accounted for about $46.1 \%$ (1,698 cases) of the total infection cases from the four West African countries affected by the Ebola epidemic. This is followed by Sierra Leone which accounted for about $33.0 \%$ (1,216 infection cases) of the total infection cases by end August 2014. Guinea and Nigeria also accounted for about 21.0\% (771 cases) and $0.6 \%$ ( 21 cases) of total infections cases, respectively.

Figure 2 Ebola virus infection cases by country in August 2014 (see online version for colours)

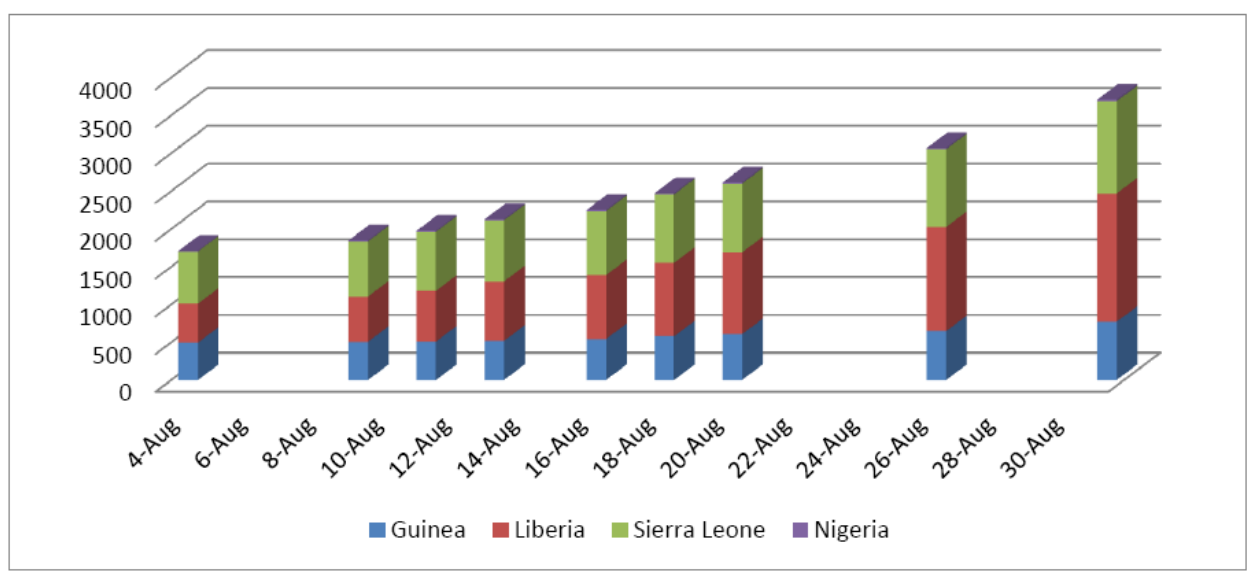

Source: WHO updates on Ebola outbreak in West Africa

With respect to death-related cases, Figure 3 shows that Liberia also recorded the highest number of deaths related to the Ebola virus infection by end August, 2014. As of 31st August 2014, the distribution of Ebola death-related cases for Guinea, Liberia, Sierra Leone and Nigeria were $26.8 \%, 47.3 \%, 25.9 \%$ and $0.38 \%$, respectively. 
Figure 3 Ebola deaths-related cases by country in August 2014 (see online version for colours)

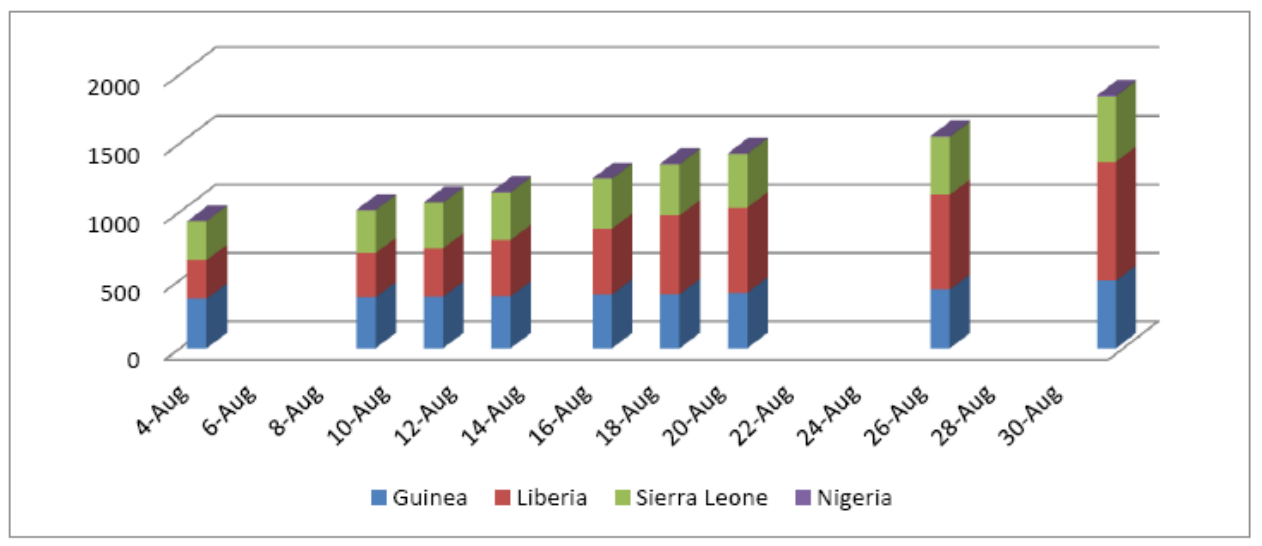

Source: WHO updates on Ebola outbreak in West Africa

The gravity of the Ebola outbreak in West Africa during the month of August became so frustrating that those countries that are hardest hit were better described by Reuter's publication of 2nd September 2014 which says - "Doctors in Liberia were out on strike as they struggled to cope with the worst outbreak of Ebola on record, while the global aid organisation Medecins Sans Frontieres (MSF) said 800 more beds for Ebola patients were urgently needed in the Liberian capital Monrovia alone, while in Sierra Leone highly infectious bodies were rotting in the streets". Furthermore, the WHO warned that - "The Ebola epidemic in West Africa could infect more than 20,000 people and spread to more countries. With a fatality rate of $52 \%$, the death toll stood at 1,552 as of Aug. 26". In another development, Reuter reported that the director of the US Centers for Disease Control and Prevention, Dr. Thomas Frieden, said he expected the outbreak to accelerate and urged governments to act now. Dr. Frieden further said that - "We're likely to see significant increases in cases. Already we have widespread transmission in Liberia. In Sierra Leone, we're seeing strong signs that that will happen in the near future", All these justify describing the situation in those countries hardest hit by the Ebola virus disease as catastrophic or out of control. The trend continued like this as an update from WHO revealed that by 21 January 2015 the number of EBOINF cases stood at 21,724 with a total of 8,641 deaths. The cases were distributed as follows: Guinea, 2,871 infection cases with 1,876 deaths; Liberia, 8,478 infection cases with 3,605 deaths; Sierra Leone, 10,340 infection cases with 3,145 deaths; Mali, eight infection cases with six deaths; Senegal, one infection case with zero death; Spain, one infection case with zero death; the UK, one infection case with zero death; and the USA, four infection cases with one death.

\section{Literature review on Ebola virus outbreaks}

It is worth noting that despite the 2014 Ebola outbreak in West Africa has been widely acknowledged as one of the world's most devastating outbreak, the Ebola virus disease has been on the rampage since 1976 when it first emerged in a location called Yambuku in Zaire (WHO, 1978b). Since then, Netesov et al. (2004) note that four main different species of the Ebola virus has been identified by the International Committee on 
Taxonomy of Viruses-Zaire Ebolavirus (EBOV), Sudan Ebolavirus (SUDV), Reston ebolavirus (RESTV) and Tai Forest Ebolavirus (TAFV). Another species known as Bundibugyo Ebolavirus or Ebola-Bundibugyo (BDBV) was also identified by the WHO and the Centre for Disease Control and Prevention (CDC) following the Ebola outbreak in Uganda in 2007.

The Ebola virus disease is mainly transmitted from animals like monkeys, bats and pigs to human beings. In Africa, the WHO note that fruit bats, particularly species of the genera Hypsignathus monstrosus, Epomops franqueti and Myonycteris torquata are the most possible natural hosts for Ebola virus. In most other African cases, Ebola virus infection has been transmitted to human beings through the handling of infected chimpanzees, gorillas, monkeys, forest antelope and porcupines found ill or dead or in the rainforest (WHO). The disease is by direct contact with the blood, secretions, organs or other bodily fluids of infected people as well as indirect contact with environments contaminated with such fluids. In most Ebola virus infected areas, healthcare workers that are not well protected with appropriate equipment stand the risk of contact the disease through direct contact with infected persons.

According to WHO (1978b), the first Ebola outbreak in Africa started since August 1976 around the Bumba Zone of the Equateur region in Zaire. Between 1st September and 24 October 1976, 318 cases of acute haemorrhagic fever affected people in the northern part of Zaire. Most of the cases occurred within a radius of $70 \mathrm{~km}$ of Yambuku. This outbreak resulted in a total of 280 deaths with only 38 serologically confirmed survivors (CFR of $88 \%$ ). Although this outbreak affected all ages and sexes, however, women between the ages of 15 and 29 years of age suffered the highest incidence of the disease. Active surveillance disclosed that the cases occurred in 55 of some 550 villages that were examined house-by-house in Zaire.

In another study, Heymann et al. (1980) show that Ebola virus was rediscovered from a nine-year-old girl who died of acute hemorrhagic fever in June 1977 at Tandala Hospital in Northwestern Zaire, in the first reported recognised case of this disease since the discovery epidemics of 1976 in Zaire and Sudan. Investigations undertaken in the Tandala region revealed that two previous clinical infections with Ebola virus had occurred in 1972 and that about $7 \%$ of the residents had immunofluorescent antibodies to the virus. Females younger than 30 years of age had a higher prevalence of antibodies than males of comparable age, but above the age of 30 years there was no sex difference.

Baron et al. (1979) also report a large outbreak of haemorrhagic fever in Southern Sudan between June and November 1976 an incidence of 284 cases that resulted to 151 deaths (CFR of 55\%). The geographical distribution of this outbreak was; 67 cases in the source town of Nzara, 213 in Maridi, three in Tembura, and one in Juba. The initial outbreak which occurred in Nzara was suspected to have originated from workers in a cotton factory. In Maridi where the largest number of cases occurred, it was due to transmissions from a large hospital. This outbreak also resulted in many medical workers infected by the disease. This outbreak started with influenza-like syndrome, including fever, headache, and joint and muscle pain, and latter causing diarrhoea, vomiting, chest pain and rash.

Baron et al. (1983) also report that between 31 July and 6 October 1979, 34 cases of the Ebola virus disease were confirmed amongst five families in a rural district of Southern Sudan that resulted to 22 deaths (CFR of 65\%). According to this study, the disease was introduced to these families from a local hospital around Nzara, Maridi. The outbreak was said to have been a recurrence at the same site as the 1976 Ebola outbreak 
in Sudan. Chains of secondary spread amongst family members account for about $85 \%$ of the cases mostly through direct physical contact with an infected person. Among all persons with such contacts in the family setting, those who provided nursing care for infected persons had a 5.1 fold increased risk of being infected by the virus.

Hayes et al. (1992) report an outbreak of Ebola-related disease in the USA. According to this study, there was a detection of an Ebola-like virus from cynomolgus macaques imported into the USA from The Philippines; studies were initiated to document transmission at export facilities located in the latter country. At one export facility, $52.8 \%$ of 161 monkeys that died over a 2.5 -month period were shown to be infected with this virus. A CFR of $82.4 \%$ was documented for the infected monkeys. The initial anti-viral antibody prevalence among the captive macaques at this facility was $25.9 \%$ (indirect fluorescent antibody titre greater than or equal to 1:16). Follow-up documented infection of $24.4 \%$ of initially seronegative animals and $8.7 \%$ of initially seropositive monkeys.

Another study by Georges et al. (1999) shows that from the end of 1994 to the beginning of 1995, 49 patients with hemorrhagic symptoms were hospitalised in the Makokou General Hospital in Northeastern Gabon. The epidemic, known as the fall 1994 epidemic, ended six weeks later. However, some aspects of this epidemic were atypical of Yellow Fever infection, so a retrospective check for other etiologic agents was undertaken. Ebola (EBO) virus was found to be present concomitantly with Yellow Fever virus in the epidemic. Two other epidemics (spring and fall 1996) occurred in the same province. GP and L genes of EBO virus isolates from all three epidemics were partially sequenced, which showed a difference of less than $0.1 \%$ in the base pairs. Sequencing also showed that all isolates were very similar to subtype Zaire EBO virus isolates from the Democratic Republic of the Congo. With regards to the re-emergence of Ebola hemorrhagic fever (EHF) in the Democratic Republic of Congo, a study by Khan et al. (1999) show that in May 1995, an international team characterised and contained an outbreak of EHF in Kikwit, Democratic Republic of the Congo. In this outbreak, the study noted that active surveillance was instituted using several methods, including among other house-to-house search, interview of healthcare personnel, retrospective contact tracing as well as a direct follow-up of suspect cases. This outbreak recorded a total of 315 cases of EHF, with an $81 \%$ case fatality. The earliest documented case-patient had onset on 6 January, and the last case-patient died on 16 July. Eighty cases $(25 \%)$ occurred among healthcare workers. Two individuals were suspected to have been the source of infection for more than 50 cases. This outbreak was terminated by the initiation of barrier-nursing techniques, health education efforts, and rapid identification of cases.

Okware et al. (2002) report an outbreak of Ebola disease from Gulu district, Uganda, on 8 October 2000. According to this study, the outbreak was characterised by fever and haemorrhagic manifestations affecting health workers and the general population of Rwot-Obillo, a village $14 \mathrm{~km}$ north of Gulu town. The outbreak was later reported to have spread to other parts of the country including Mbarara and Masindi districts. Response measures included surveillance, community mobilisation, and case and logistics management. The international response on this outbreak was coordinated by the WHO under the Global Outbreak and Alert Response Network. This outbreak lasted up to 16 January 2001 , recording a total of 425 cases with 224 deaths countrywide, bringing the CFR to $53 \%$. The infection rate was highest amongst women on average. The country 
was, however, declared Ebola free on 27 February 2001, 42 days after the last case was reported. Further review of the literature revealed that many other countries including the Cote d'Ivoire, South Africa, and the Democratic Republic of Congo have all suffered from some sort of Ebola virus outbreak. A summary of the review of the literature on the chronology of the Ebola virus disease outbreaks is presented Table A2 of Appendix.

From the review of the literatures so far, no study has apparently done a critical assessment on the economic impact of the Ebola virus epidemic in countries infected by the disease using an econometric approach. This study is, therefore, expected to contribute to the existing body of literature on Ebola outbreaks by employing an econometric-based methodology to evaluate the impact of the Ebola virus epidemic on the economies of those countries affected by the disease.

\section{Methodology and estimation techniques}

\subsection{Model specification}

In this study, we are interested in establishing an empirical relationship between the outbreak of an epidemic (in this case Ebola) and some key economic variables of interest in countries affected by the epidemic. In most cases, when there is an outbreak of an epidemic, it will directly or indirectly affect economic performance by slowing down gross domestic product (GDP), reducing government revenues, raising government spending on health in trying to combat the epidemic, exerts upward pressure on COMPR as the epidemic slowdown the supply side, etc. As the gravity of the epidemic intensifies, it may cause a severe restriction in the free movement of people and goods, increase in death rates and hence impose adverse effects on labour productivity, capital formation and disruption of normal economic activities.

As the Ebola epidemic is ongoing at the time of carrying out this study, the study utilises an event study-type approach in carrying out the analysis. One of the key challenges confronting this study, however, is the fact that it is extremely very difficult to get all the required data on the key economic variables of interest since the outbreak is ongoing. That is, as the epidemic was ongoing at the time of carrying out the study, it is extremely difficult to tell exactly by how much government revenues, government spending, COMPR and economic growth have fallen or risen. On account of this, the best bet is to make use of public opinion regarding the direction towards which these variables are likely heading to as the outbreak intensifies. In doing so, the study made use of various national publications in the affected countries as well as those of the International Monetary Fund (IMF), the World Bank, Reuters, BBC, CNN, the WHO, the West African Health Organization (WAHO) and the Center for Disease Control and Prevention (CDC) in assessing general opinions on the perceived impact of the Ebola epidemic on key economic variables such as economic growth, inflation, and budget deficits (BUDEFs). For instance, if the general public believed that the outbreak will lead to a decline in economic growth in those countries affected, then we can generate a binary response variable for economic growth that takes the value 1 if there is a decrease in growth and 0 otherwise. Similarly, if the general public believed that COMPR are 
adversely affected the Ebola epidemic, we can generate a binary response variable for COMPR that takes the value 1 if COMPR rise and 0 otherwise. We can thus generate binary response variables for key socioeconomic variables of interest based on public opinions. Given that the dependent variables to be used in this study are binary response variables, the question now is which econometric model is more appropriate in carrying out such an empirical analysis?

A critical review of econometric techniques apprises this study that, in qualitative response models, the variables to be explain, $y$, is a random variable taking on a finite number of outcomes. The leading case occurs when $y$ is a binary response taking on the values zero and one, which indicate whether or not a certain event has occurred. Regardless of the definition of $y$, it has been a common practice to refer to $y=1$ as a success and $y=0$ as a failure. In this type of models, the general interest lies primarily in estimating the response probability:

$$
P(X) \equiv P(y=1 \mid X)=P\left(y=1 \mid x_{1}, x_{2}, \ldots, x_{k}\right)
$$

For a continuous variable, $x_{j}$, the partial effect of $x_{j}$ on the response probability is given as:

$$
\frac{\partial P(y=1 \mid x)}{\partial x_{j}}=\frac{\partial P(x)}{\partial x_{j}}
$$

If, however, $x_{j}$ is a binary explanatory variable, the partial effect of $x_{j}$ on the response probability is estimated as:

$$
P\left(x_{1}, x_{2}, \ldots, x_{k-1}, 1\right)-P\left(x_{1}, x_{2}, \ldots, x_{k-1}, 0\right)
$$

where equation (3) is the difference in response probability when $x_{k}=1$ and $x_{k}=0$. For most qualitative response models, whether a variable $x_{j}$ is continuous or discrete, the partial effect of $x_{j}$ on $P(x)$ depends on all $x$. The probit model is a special case of binary response models with a cumulative distribution function (CDF) that takes the form:

$$
G(z)=\varphi(Z)=\int_{-\infty}^{z} \varnothing(v) d v
$$

where $\varnothing(z)$ is the standard normal density $\varnothing(z)=(2 \pi)^{-\frac{1}{2}} \exp \left(-\frac{z^{2}}{2}\right)$. Similarly, the logit model is another special case of equation (1) with a cumulative density function (CDF) that tales a standard logistic distribution of the form;

$$
G(z)=\theta(z) \equiv \exp (z) /[1+\exp (z)]
$$

Logit and probit models are most suitable for such analysis. This is because they are both useful when we want to fit a linear regression model to a binary response variable. Here, we assume that a response variable $y$ is binary, that is, can have two possible outcomes denoted as 1 or 0 as indicated earlier. For a detail discussion of these models, see Wooldridge (2000a, 2000b, 2000c), Albert and Chib (1993), Bliss (1935, 1938), McCullagh and Nedler (1989), Goldberger (1991) and Greene (1997). 


\subsubsection{Choice of variables}

\subsubsection{Dependent variables}

This study will focus on three key economic variables of interest - economic growth (growth), COMPR, and government BUDEF. These variables will be treated as binary response variables in assessing the economic impact of the Ebola outbreak in the West African States of Guinea, Liberia, Sierra Leone and Nigeria. The variable economic growth is used to capture the relative effect of the Ebola outbreak on the general economic performance of the country's GDP. This is because, during the outbreak of an epidemic, gross domestic output is most likely to be adversely affected through a decline in the productivity of labour arising from illness and death cases from the country's active labour force. The variable representing COMPR is also considered as an important response variable because, during the course of an epidemic outbreak, the market forces of demand and supply will be in disequilibrium as the supply side declines due to declining productivity, thereby forcing COMPR to rise. BUDEFs of the central government are equally expected to rise as government spending on health to contain the epidemic rises whilst government revenues from taxation are declining as normal economic activities are being disrupted by the outbreak.

\subsubsection{Explanatory variables}

Following the approach by Bandiera et al. (2000) and Laeven (2001), this study attempted to generates an Ebola severity index (IES) to capture the degree of severity of the disease in each of the countries affected by the disease at different time period. In doing so, we consider the following factors - outbreak of the Ebola virus infection, the CFR, international border closure, governments' declaration of an emergency as the gravity of the outbreak becomes alarming, quarantining of regions/areas within the same country, cancellation or stoppage of flights by airlines to the country, closure of educational institutions owing to the outbreak, and closure of the whole country owing to the disease. If, for instance, the country declares an outbreak of the Ebola virus disease, we assign a value of 1 or 0 if not. We did the same for the other factors considered above except for CFR which is the percentage of death cases arising from the infection cases. For the CFR, if no death occurs, we assign a value of 0 . If the CFR is less than $30 \%$ we assign a value of 1 . If the CFR is between $30 \%$ and $70 \%$ we assign a value of 2 . If the CFR is above $70 \%$ we assign a value of 3 .

For each time period, we compile the ESI for each country based on the aforementioned criteria. By summing up the scores from all the criteria listed above, we get a maximum possible score of 10 and a minimum score of 0 . Thus, the ESI will range from 0 to 10. If the ESI is 0 , it means that there is no issue of Ebola in that country at that particular time period. As the index moves towards 10, it implies that the Ebola outbreak is becoming more and more severe in that country at that particular point in time. Using this innovative approach, the study computed the ESI for Guinea, Liberia, Serra Leone and Nigeria for each time period and presented the result in Table A1 of Appendix. This index is then used as one of the explanatory variables in assessing the economic impact of Ebola in the affected countries. Table 3 presents a summary of both the dependent and explanatory variables and their definitions. 
Table 3 Description of variables

\begin{tabular}{|c|c|}
\hline Variable & Definitions \\
\hline \multicolumn{2}{|l|}{ Dependent variables } \\
\hline Economic growth (growth) & $\begin{array}{l}=1 \text { if growth is adversely affected by the outbreak, } 0 \\
\text { otherwise. }\end{array}$ \\
\hline Commodity prices (COMPR) & $=1$ if prices rise following the outbreak, 0 otherwise. \\
\hline Budget deficits (BUDEFs) & $\begin{array}{l}=1 \text { if budget deficit is adversely affected by the outbreak, } 0 \\
\text { otherwise }\end{array}$ \\
\hline \multicolumn{2}{|l|}{ Explanatory variables } \\
\hline Ebola severity index (ESI) & $\begin{array}{l}\text { This index takes values between } 0 \text { and } 10 \text { depending on the } \\
\text { severity of the outbreak }\end{array}$ \\
\hline Case fatality rate (CFR) & $\begin{array}{l}=0 \text { if no death occur, }=1 \text { if the death rate is less than } 30 \%,=2 \\
\text { if the death rate is between } 30 \% \text { and } 70 \%,=3 \text { if the death rate } \\
\text { is more than } 70 \% \text {. }\end{array}$ \\
\hline International isolation (ISOL) & $\begin{array}{l}=0 \text { if there is no kind of restriction affecting the free } \\
\text { movement of persons from that country, } 1 \text { if the country's } \\
\text { citizens face some form of discrimination when crossing } \\
\text { borders to neighbouring countries, } 2 \text { if the country's citizens } \\
\text { are severely harassed when crossing borders to neighbouring } \\
\text { countries, } 3 \text { if land borders are completely closed down } \\
\text { thereby deterring free movement of persons and goods across } \\
\text { borders in neighbouring countries, } 4 \text { if international airlines } \\
\text { stop or cancel flights from going to the Ebola virus infected } \\
\text { country }\end{array}$ \\
\hline EBOINF & $\begin{array}{l}\text { Cumulative number of confirmed Ebola virus infection cases } \\
\text { in that country as updated by WHO. }\end{array}$ \\
\hline
\end{tabular}

Source: Author's generation of variables based on certain criteria and public opinion

\subsubsection{Estimation issues}

In this study, we pooled data from four Ebola virus infected West African countries of Guinea, Liberia, Sierra Leone and Nigeria over the period March to August (estimation window). The pooling of data from cross-sectional units over a given time period of time constitute what is referred to as longitudinal or panel data. This, therefore, requires the use of an estimation technique that is in conformity with panel data estimation procedures. Consequently, the specified model as presented in equation (1) will now take the form:

$$
P\left(y_{i t}=1 \mid x_{i t}\right)=G\left(x_{i t} \beta\right), \quad t=0,1,2, \ldots, T
$$

where $G($.$) is a known function taking on values in the open unit interval, and x_{i t}$ represents a variety of factors, including time dummies, interaction of time dummies with time-constant or time-varying variables. In this formulation, we can obtain a consistent estimator of $\beta$ by maximising the partial log likelihood function $\sum_{i=1}^{N} \sum_{t=1}^{T}\left\{y_{i t} \log G\left(x_{i t} \beta\right)+\left(1-y_{i t}\right) \log \left[1-G\left(x_{i t} \beta\right)\right]\right\}$ using pooled estimation technique. A robust variance matrix estimator is needed to account for serial correlation 
in the scores across $t$. In the event the model represented in equation (6) above turns out to be dynamically complete (i.e., $P\left(y_{i t}=1 \mid x_{i t}, y_{i, t-1}, x_{i, t-1}, \ldots\right)=P\left(y_{i t}=1 \mid x_{i t}\right)$ ), all the usual statistics from a probit or logit model that pools observations and treats the sample as a long independent cross-section of size NT are valid, including likelihood ratio statistics. In its simplest form, dynamic completeness implies that the scores are serially uncorrelated across $t$, a key condition for the standard inference procedures to be valid (Wooldridge, 2000a)

To test for dynamic completeness, we added a lagged dependent variable and possibly lagged explanatory variables. For concreteness, we focus on the probit case since other indexed models are handled in a similar fashion. Suppose we define $u_{i t} \equiv y_{i t}-\Phi\left(x_{i t} \beta\right)$, so that under the assumption of dynamic completeness, $E\left(u_{i t} \mid x_{i t}, y_{i, t-1}\right.$, $\left.x_{i, t-1}, \ldots\right)=0$, for all $t$. It therefore implies that $u_{i t}$ is uncorrelated with any function of the variables $\left(x_{i t}, y_{i, t-1}, x_{i, t-1}, \ldots\right)$, including $u_{i t-1}$. Thus, it can be observed that it is serial correlation in $u_{i t}$ that makes the usual inference procedures invalid. In practice, we employ a simple test using pooled probit to estimate the artificial model;

$$
P\left(y_{i t}=1 \mid x_{i t}, u_{i . t-1}\right)=\Phi\left(x_{i t} \beta+\gamma_{1} u_{i, t-1}\right)
$$

From the above formulation, the null hypothesis is $H_{0}: \gamma_{1}=0$. If $H_{0}$ is rejected, then the assumption of dynamic completeness does not hold. This is a case where under the null hypothesis, the estimation of $\beta$ required to obtain $u_{i, t-1}$, does not affect the limiting distribution of any of the usual test statistics, that is the Wald, LR or LM, of $\mathrm{H}_{0}: \gamma_{1}=0$. The Wald statistics (i.e., the $t$ statistics on $\gamma_{1}$ ) is the easiest to obtain amongst them. For the LM and LR statistics, it requires the dropping of the first time period in estimating the restricted model $\left(\gamma_{1}=0\right)$. This study will therefore employ the Wald test to check the estimated model for dynamic completeness as a way of addressing potential problems associated with serial correlation.

\section{Presentation and interpretation of estimation results}

\subsection{Presentation of results}

We start this section by presenting the summary statistics. As shown in Table 4, the study used 100 observations pooled across the affected countries of Guinea, Liberia, Sierra Leone and Nigeria. The study uses weekly data on Ebola-related variables using WHO updates. As can be noted in Table 4, there is a mean time period of 23.38 with a standard deviation of 10.53, implying that the panel data is unbalanced. For a balanced panel, the standard deviation of the time variable is 0 , implying equal time period across the cross-sectional units. The summary statistics also indicate that the mean number of Ebola virus infection cases (EBOINF) is 326.87 with a standard deviation of 350.87 . The high standard deviation implies that the number of cases significantly differ from country to country. For instance, whilst Liberia recorded 1698 infection cases as of 31 August 2014 Nigeria only recorded 21 cases. As for the CFR, the mean value for the four countries is $52.3 \%$ with a standard deviation of 16.396 .

With regards the binary response variables, the summary statistics as shown in Table 4 indicates that COMPR has a mean value of 0.72 with a standard deviation of 0.45126 . This implies that $72 \%$ of opinions from the general public strongly support the 
fact that the Ebola outbreak will exert an upward pressure on COMPR particularly in those countries hardest hit be the virus. The economic growth variable (growth) has a mean of 0.61 with a standard deviation of 0.490207 . This implies that $61 \%$ of perceptions were of the view that the outbreak will negatively affect economic growth in countries hardest hit by the disease. Finally, the BUDEF variable has a mean of 0.84 with a standard deviation of 0.36826 , implying that about $84 \%$ of the views are in support of the fact that the outbreak will worsen BUDEFs in those countries hardest hit by the Ebola epidemic.

Table 4 Presentation of summary statistics

\begin{tabular}{|c|c|c|c|c|c|c|}
\hline Variables & No. obs. & Mean & Std. dev. & \multicolumn{2}{|c|}{ Minimum } & Maximum \\
\hline ID & 100 & 1.99 & 0.969171 & \multicolumn{2}{|c|}{1} & 4 \\
\hline Time & 100 & 23.38 & 10.53113 & \multicolumn{2}{|c|}{1} & 39 \\
\hline EBOINF & 100 & 326.87 & 350.8793 & \multicolumn{2}{|c|}{8} & 1698 \\
\hline Deaths & 100 & 181.2 & 184.6327 & \multicolumn{2}{|c|}{1} & 871 \\
\hline CFR & 100 & $52.32 \%$ & 16.39638 & \multicolumn{2}{|c|}{$7.4 \%$} & $78.8 \%$ \\
\hline ISOL & 100 & 1.31 & 1.331021 & \multicolumn{2}{|c|}{0} & 3 \\
\hline COMPR & 100 & 0.72 & 0.451261 & \multicolumn{2}{|c|}{0} & 1 \\
\hline Growth & 100 & 0.61 & 0.490207 & \multicolumn{2}{|c|}{0} & 1 \\
\hline BUDEF & 100 & 0.84 & 0.368261 & \multicolumn{2}{|c|}{0} & 1 \\
\hline \multicolumn{7}{|c|}{ Its from the logit and probit mode } \\
\hline \multirow[b]{2}{*}{ Variables } & \multicolumn{3}{|c|}{ Logit model } & \multicolumn{3}{|c|}{ Probit model } \\
\hline & $\begin{array}{l}\text { Growth } \\
\text { (1) }\end{array}$ & $\begin{array}{c}C O M P R \\
\text { (2) }\end{array}$ & $\begin{array}{c}B U D E F \\
\text { (3) }\end{array}$ & $\begin{array}{l}\text { Growth } \\
\text { (1) }\end{array}$ & $\begin{array}{c}\text { COMPR } \\
\text { (2) }\end{array}$ & $\begin{array}{c}B U D E F \\
\text { (3) }\end{array}$ \\
\hline \multirow[t]{2}{*}{ Constant } & -3.443 & ------- & -1.2091 & -1.7482 & -1.4981 & --------- \\
\hline & $(-1.73)$ & & $(-0.88)$ & $(-1.96)^{* *}$ & $(-1.72)$ & \\
\hline \multirow[t]{2}{*}{ EBOINF } & 0.02116 & 0.02015 & 0.01265 & 0.011204 & 0.01179 & 0.00597 \\
\hline & $(2.62)^{* * *}$ & $(5.85)^{* * *}$ & $(2.11)^{* *}$ & $(2.77)^{* * *}$ & $(2.61)^{* * *}$ & $(2.66)^{* * *}$ \\
\hline \multirow[t]{2}{*}{ CFR } & 0.0395 & 0.02948 & -0.03701 & 0.01938 & -0.14282 & -0.009245 \\
\hline & $(1.06)$ & $(0.73)$ & $(-1.22)$ & (1.09) & $(-0.82)$ & $(-0.58)$ \\
\hline \multirow[t]{2}{*}{ ESI } & 0.8112 & -------- & 0.91225 & 0.42403 & 0.29804 & 0.11845 \\
\hline & $(1.38)$ & & $(1.15)$ & $(1.41)$ & $(0.69)$ & $(0.45)$ \\
\hline \multirow[t]{2}{*}{ ISOL } & 2.8944 & 1.0755 & 1.6875 & 1.5346 & 1.04899 & 0.75311 \\
\hline & $(3.08)^{* * *}$ & $(1.65)$ & $(1.15)$ & $(3.30)^{* * *}$ & $(2.39)^{* * *}$ & $(1.78)$ \\
\hline No. of obs. & 100 & 100 & 100 & 100 & 100 & 100 \\
\hline \multicolumn{7}{|l|}{ Wald test } \\
\hline $\operatorname{Chi2}(4)=$ & 17.0 & 14.41 & 55.69 & 21.68 & 20.53 & 59.49 \\
\hline Prob $>$ Chi $2=$ & $(0.0019)$ & $(0.0061)$ & $(0.0000)$ & $(0.0002)$ & $(0.0004)$ & $(0.0000)$ \\
\hline
\end{tabular}

Notes: A positive coefficient means the explanatory variable adversely affect the dependent variable based on the definition of our binary response variables, and where $(* * *),(* *)$ and $(*)$ implies parameter significance at the $1 \%, 5 \%$ and $10 \%$ level, respectively. 
Table 5 shows the estimation results from both the logit and probit models. As shown in Table 5, we estimated three different equations numbered 1 to 3 for both the logit and probit models.

The coefficients of equations (1), (2) and (3) show the relatives effects of the explanatory variables on the binary response variables representing economic growth (growth), COMPR and BUDEFs, respectively. For each of the estimated equations, we present the results of the Wald test to evaluate the dynamic completeness of the model. The results from the Wald test as shown in the lower panel of Table 5 indicate that all the estimated equations are dynamically complete, implying the absence of serial correlation in each of the estimated equations. This is a guarantee that inferences made from the estimated equations are valid.

\subsection{Interpretation of the results}

As presented in Table 5, the coefficients of one two of explanatory variables representing EBOINF cases and the index of ISOL are consistently significant in all the equation. The other explanatory variables - the ESI and CFR have the appropriate signs but rather insignificant. As can be observed in Table 5, for both the Logit and the Probit models, the variables representing Ebola virus infection (EBOINF) exerts a significantly adverse impact on economic growth (growth), COMPR and worsen BUDEFs in the countries hardest hit by the outbreak. This result is consistent with that of the general perception that the outbreak of the Ebola virus epidemic will adversely affect economic growth, COMPR and BUDEFs in countries hardest hit by the Ebola outbreak. The coefficients of the isolation variable (ISOL) are also significant in both the logit and probit equations, implying that the act of isolating countries hardest hit by the epidemic contributed significantly in worsening the adverse effects of the outbreak on economic growth, COMPR and BUDEFs. This result is consistent with WHO's warning that isolating countries suffering from the Ebola epidemic will be detrimental to countries suffering from the outbreak.

From the above analysis, it is thus important to note that the key factors contributing to worsening the economic conditions of countries hardest hit by the 2014 Ebola outbreak in West Africa were the soaring number of infection cases and the ISOL of these countries at a time when they needed other countries most for possible assistance in combating the outbreak. The ISOL which came in the form of land border closure as well as stopping of airlines from going to the affected countries resulted in hindering the transportation of the requisite healthcare equipment, medicines and medical experts from other parts of the world to help combat the outbreak, thereby creating an avenue for worsening the spread of the disease. Furthermore, the isolation made it difficult to make available requisite commodities like petroleum products, imported food stuff and other necessities, contributing to putting pressure on COMPR as existing stock continues to dwindle. The ISOL also resulted in squeezing out government revenues sources as tax revenues from imports continues to fall at a times when government spending on health to combat the disease is skyrocketing. These and many other factors constituted the key channels through which the act of isolating countries hardest hit by the outbreak adversely impact on the socio-economic conditions of those countries.

Interestingly, a good number of reports on the economic impact of the 2014 Ebola outbreak in West Africa provided evidences that strongly support the findings from this study. The World Bank (2014), for instance, uses a methodology based on sector 
decomposition and estimated the short-term impact of the Ebola outbreak on output at around 2.1 percentage points (pp) of GDP in Guinea (reducing growth from $4.5 \%$ to $2.4 \%$ ); $3.4 \mathrm{pp}$ of GDP in Liberia (reducing growth from $5.9 \%$ to $2.5 \%$ ) and $3.3 \mathrm{pp}$ of GDP in Sierra Leone (reducing growth from $11.3 \%$ to $8.0 \%$ ). The expected forgone output in these three West African countries is estimated at around US\$359 million in 2014 prices. In the medium-term (2015), the World Bank estimated that the loss of output in Guinea will be negligible under Low Ebola, and 2.3 pp of GDP under High Ebola. In Liberia, it is estimated at $4.2 \mathrm{pp}$ of GDP under Low Ebola, or 11.7 pp of GDP under High Ebola. In Sierra Leone, the impact would be $1.2 \mathrm{pp}$ of GDP under Low Ebola, and $8.9 \mathrm{pp}$ of GDP under High Ebola. These estimates of lost GDP in the core three countries (for 2015 alone) sum up to around US\$97 million under Low Ebola, and US\$809 million under high Ebola.

The World Bank report further revealed that the short-term fiscal impacts are also large, estimated at around US\$93 million (4.7\% of GDP) for Liberia; US\$79 million (1.8\% of GDP) for Sierra Leone and US\$120 million (1.8\% of GDP) for Guinea. With regards to inflation, the report indicates that food prices were initially contained but are now showing upward movements in response to shortages, panic buying, and speculation. Also, exchange rate volatility has increased in all the three countries, particularly since June, fuelled by uncertainty and some capital flight. The World Bank report is, however, silent about Nigeria whose Ebola outbreak is deemed not severe enough to exert any significant impact on economic growth, COMPR and the fiscal position of the government in the short-term.

\section{Conclusions}

The 2014 Ebola outbreak in West Africa is one of the most devastating Ebola epidemic outbreaks in history and the first ever witnessed in West Africa. By end August 2014, a cumulative total of 3,685 Ebola virus infections cases were reported, including 1,841 deaths from the four West African countries covered by this study. Owing to the devastating pace at which the 2014 Ebola epidemic wreaked havoc West African countries, the world became increasing worried as the disease continued to spread across borders. This study, therefore, aimed at assessing the economic impact of the Ebola epidemic in West African, particularly in those countries hardest hit by the outbreak. In addition to providing an overview of the evolutionary trend of the 2014 Ebola outbreak in the four West African countries affected by the disease, the study utilises an innovative methodology that scientifically captures the contemporaneous impact of the Ebola outbreak on key economic variables of interest. The results from the study revealed that in addition to the adverse impact of the Ebola outbreak on economic condition of those countries, the isolation of these countries by their immediate neighbours as well as other countries outside the West African region contributed immensely in further worsening the socioeconomic conditions faced by these countries during the epidemic outbreak.

Most importantly, experience garnered from this study revealed that in all the three countries hardest hit by the outbreak, there are glaring manifestations of very weak healthcare systems. In most of these countries, the percentage of government budget devoted to the health sector is far below the MDGs target. This was clearly manifested by the high fatality rate amongst ill equipped healthcare workers who are highly at risk of 
contracting the disease. The inadequacy and ill equipment of isolation centres, the extremely poor incentives provided to an already grossly inadequate health working force, and the inadequacy of the technical experts were some of the major constraints in combating the outbreak.

\section{Policy recommendation}

On account of the aforementioned findings that stem from this study, the following policy recommendations are aimed at providing effective strategies for combating similar outbreak of epidemics in the future. Firstly, there is an urgent need for West African countries to strengthen their healthcare systems by increasing the allocation of the fiscal budget towards improving the health sector. Secondly, there is a strong need to increase the training of more health workers, particularly in the area of epidemiology to enhance capacity in the handling of future outbreaks of epidemics. Thirdly, there is a strong need for West African countries to strictly adhere to the ECOWAS protocol of Free Movement of Persons and goods so that when there is an outbreak of an epidemic in a member country, isolating of that member state would not result in aggravating the socioeconomic impact of the outbreak as experienced in the current Ebola. Fourthly, there is a stronger need for ECOWAS member states to establish an epidemic emergency fund through the WAHO to enhance the region's preparedness in combating similar outbreaks in the future. Fifthly, the West African region should also think of establishing a rapid response health task force that can be immediately deployed in any member state that experiences an epidemic outbreak with a view to containing the spread of the outbreak to other member states. Sixthly, there is a need for the strengthening of collaboration between WHO and leading international financial institutions (World Bank, IMF, IATA, etc.) in coordinating responses for the combating of epidemic outbreaks. Finally, there is a need for a similar study to be carried out to assess the full economic impact of the 2014 Ebola outbreak in West Africa after the current outbreak is declared over (i.e., a post Ebola outbreak study).

\section{References}

Albert, J.H. and Chib, S. (1993) 'Bayesian analysis of binary and polychotomous response data', Journal of the American Statistical Association, Vol. 88, No. 422, pp.669-679.

Bandiera, O.G., Caprio, P.H. and Schiantarelli, F. (2000) 'Does financial reforms raise or reduce savings?', Review of Economic and Statistics, Vol. 82, No. 2, pp.239-263.

Baron, R.C., McCormick, J.B. and Zubeir, O.A. (1983) 'Ebola virus disease in Southern Sudan-Hospital Dissemination and intrafamilial spread', Bulletin of the World Health Organization, Vol. 62, No. 6, pp.997-1003.

Bliss, C.I. (1935) 'The calculation of the dosage-mortality curve', Annals of Applied Biology, Vol. 22, No. 1, pp.134-167.

Bliss, C.I. (1938) 'The determination of the dosage-mortality curve from small numbers', Quarterly Journal of Pharmacology, Vol. 11, No. 2, pp.192-216.

Georges, A.J., Leroy, E.M., Renaut, A.A., Benissan, C.T., Nabias, R.J., Ggoc, M.T., Obiang, P.I., Lepage, J.P., Betherat, E.J., Benoni, D.D., Wickings, E.J., Amblard, J.P., Lansoud, S.J.M., Melleliri, J.M., Baize, S.G. and Courbot, M.C. (1999) 'Ebola hemorrhagic fever outbreaks in Gabon, 1994-1997', The Journal of Infectious Disease, February, Vol. 179, Suppl., No. 1, pp.S65-S75. 
Goldberger, A.S. (1991) A Course in Econometrics, Harvard University Press, Cambridge, MA.

Greene, W. (1997) Econometric Analysis, 3rd ed., Macmillan, New York.

Hayes, C.G., Burans, J.P., Ksiazek, T.G., Del Rosario, R.A., Miranda, M.E.G., Manaloto, C.R., Barrientos, A.B., Robles, C.G., Dayrit, M.M. and Peters, C.J. (1992) 'Outbreak of fatal illness among captive macaques in the Philippines caused by an Ebola related filovirus', Am. J. Trop. Med. Hyg., Vol. 46, No. 6, pp.664-671.

Heymann, D.L., Weisfeld, J.S., Webb, P.A., Johnson, K.M., Cairns, T. and Berquist, H. (1980) 'Ebola hemorrhagic fever: Tandala, Zaire, 1977-1978', The Journal of Infectious Disease, Vol. 142, No. 3, pp.372-376.

Khan, A.S., Tshioko, F.K., Haymann, D.L., Le Guenno, B., Nebeth, P., Kerstiens, B., Fleerackers, Y., Kilmax, P.H., Rodier, G.R., Nkuku, O., Rolin, P.E., Sanchez, A., Zaki, S.R., Swanepoel, R., Tomori, O., Nichol, S.T., Peters, C.J., Tamfum, J.J.M. and Ksiazek, T.G. (1999) 'The reemergence of Ebola hemorrhagic fever, Democratic Republic of the Congo, 1995', The Journal of Infectious Disease, Vol. 179, No. 1, pp.576-586.

Laeven, L. (2001) Financial Liberalization and Financing Constraints: Evidence from Panel Data on Emerging Economies, World Bank, Washington DC, USA.

McCullagh, P. and Nedler, J. (1989) Generalized Linear Models, Chapman and Hall, London.

Netesova, I.G., Swenson, P.D., Kalashnikova, T.V., Netesov, S.V. and Favorov, M.O. (2004) 'Subtypes of HBsAg of the hepatitis B virus in Western Siberia', Voprosy virusologii, Vol. 49, No. 1 , pp.17-20.

Okware, S.I., Omaswa, F.G., Zaramba, S., Opio, A., Lutwama, J.J., Kamugisha, J., Rwaguma, E.B., Kagwa, P. and Lamunu, M. (2002) 'An outbreak of Ebola in Uganda', Tropical Medicine and International Health, Vol. 7, No. 12, pp.1068-1075.

Wooldridge, J.M. (2000a) Introductory Econometrics: A Modern Approach, South-Western, Cincinnati, $\mathrm{OH}$.

Wooldridge, J.M. (2000b) 'A framework for estimating dynamic, unobserved effects panel data models with possible feedback to future explanatory variables', Economics Letters, Vol. 68, No. 3, pp. 245-250.

Wooldridge, J.M. (2000c) Inverse Probability Weighted M-Estimators for Sample Selection, Attrition, and Stratification, mimeo, Michigan State University Department of Economics.

World Bank (2014) The Economic Impact of the 2014 Ebola Epidemic: Short and Medium Term Estimates for Guinea, Liberia, and Sierra Leone, A World Bank Report, No. 907848, 17 September, Washington DC.

World Health Organization (WHO) (1978a) 'Ebola haemorrhagic fever in Sudan, 1976', Bulletin of the World Health Organization, Vol. 56, No. 2, pp.247-270.

World Health Organization (WHO) (1978b) 'Ebola haemorrhagic fever in Zaire, 1976', Bulletin of the World Health Organization, Vol. 56, No. 2, pp.271-293.

\section{Notes}

1 For instance, Kenya airlines cancelled its flights to West Africa. Similarly, Arik airline, The Gambia Bird, Asky, British airline, etc. all cancelled their flights to the Ebola virus hardest hit countries of Sierra Leone, Guinea and Liberia. However, Brussels airline and Marroco Airline (Air Marroc) continued to fly to these countries throughout the crisis. Nigeria was not affected by the flight cancelations.

2 Cote d'Ivoire, Mali and Guinea Bissau closed their borders with Liberia and Guinea. Similarly, Cameroon closed its border with Nigeria.

3 Countries hardest hit by the Ebola outbreak also quarantined regions with high infection rates in an attempt to control the spread of the disease within the country. 


\section{Appendix}

Table A1 Calculation of the ESI for the period February to September 2014

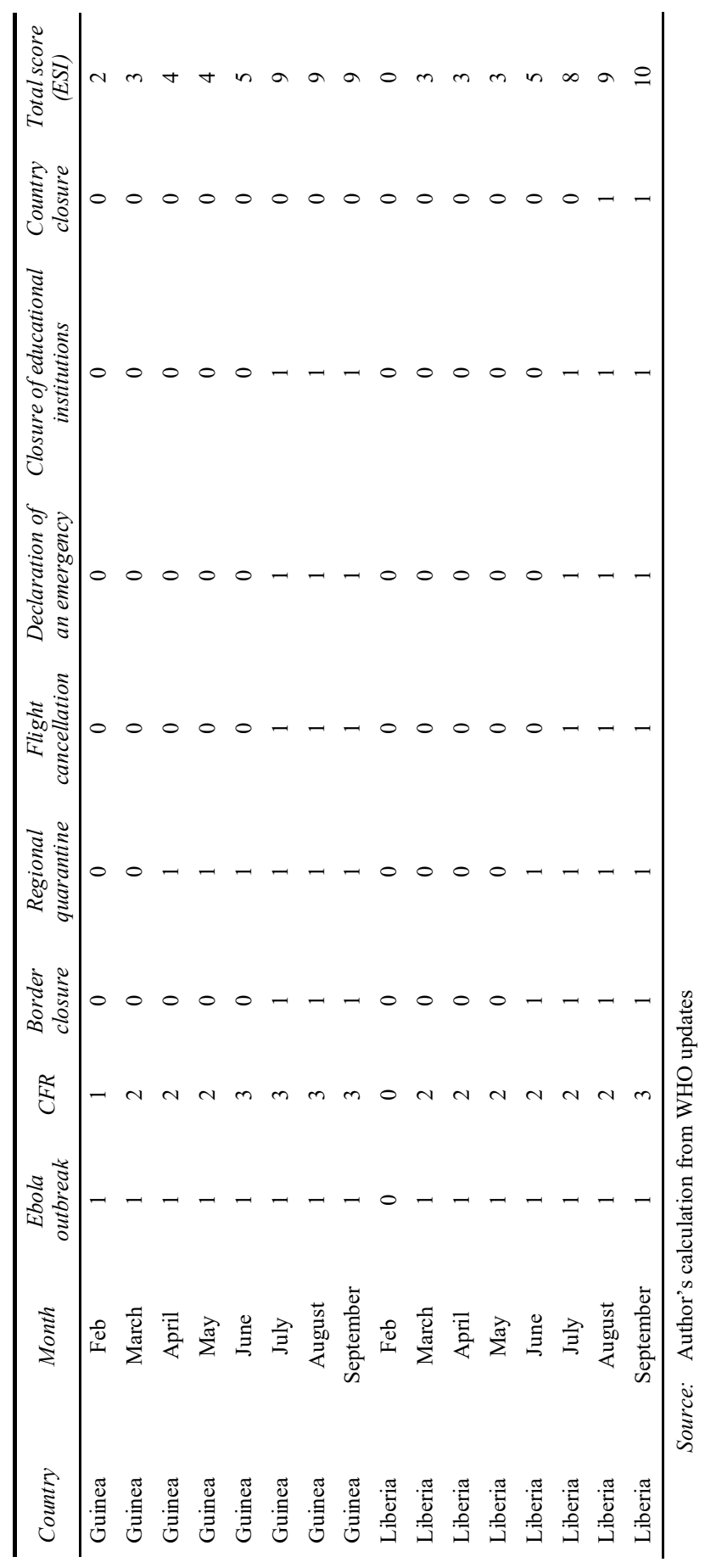


Table A1 Calculation of the ESI for the period February to September 2014 (continued)

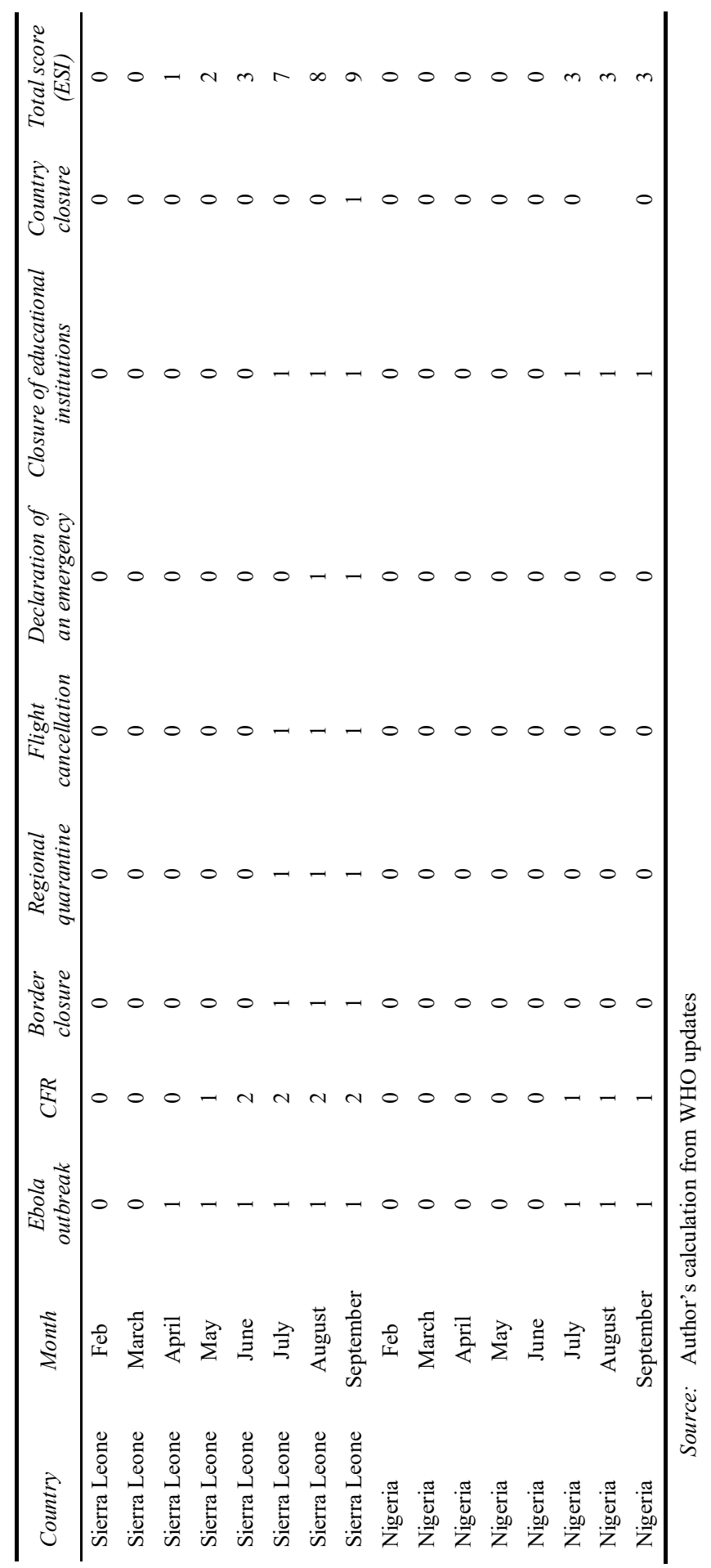


Table A2 Summary of Ebola outbreaks in Africa and in other parts of the world since 1976

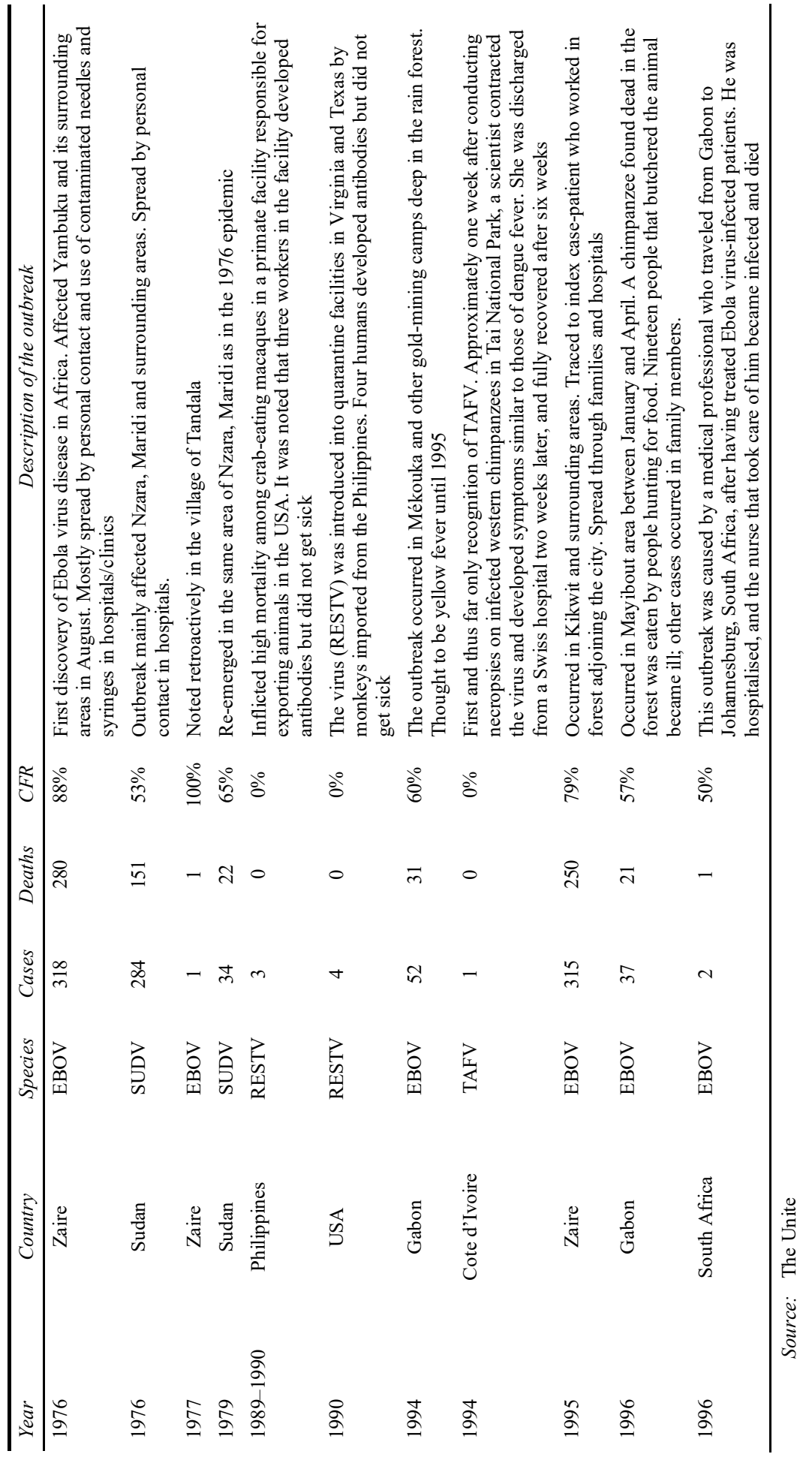


Table A2 Summary of Ebola outbreaks in Africa and in other parts of the world since 1976 (continued)

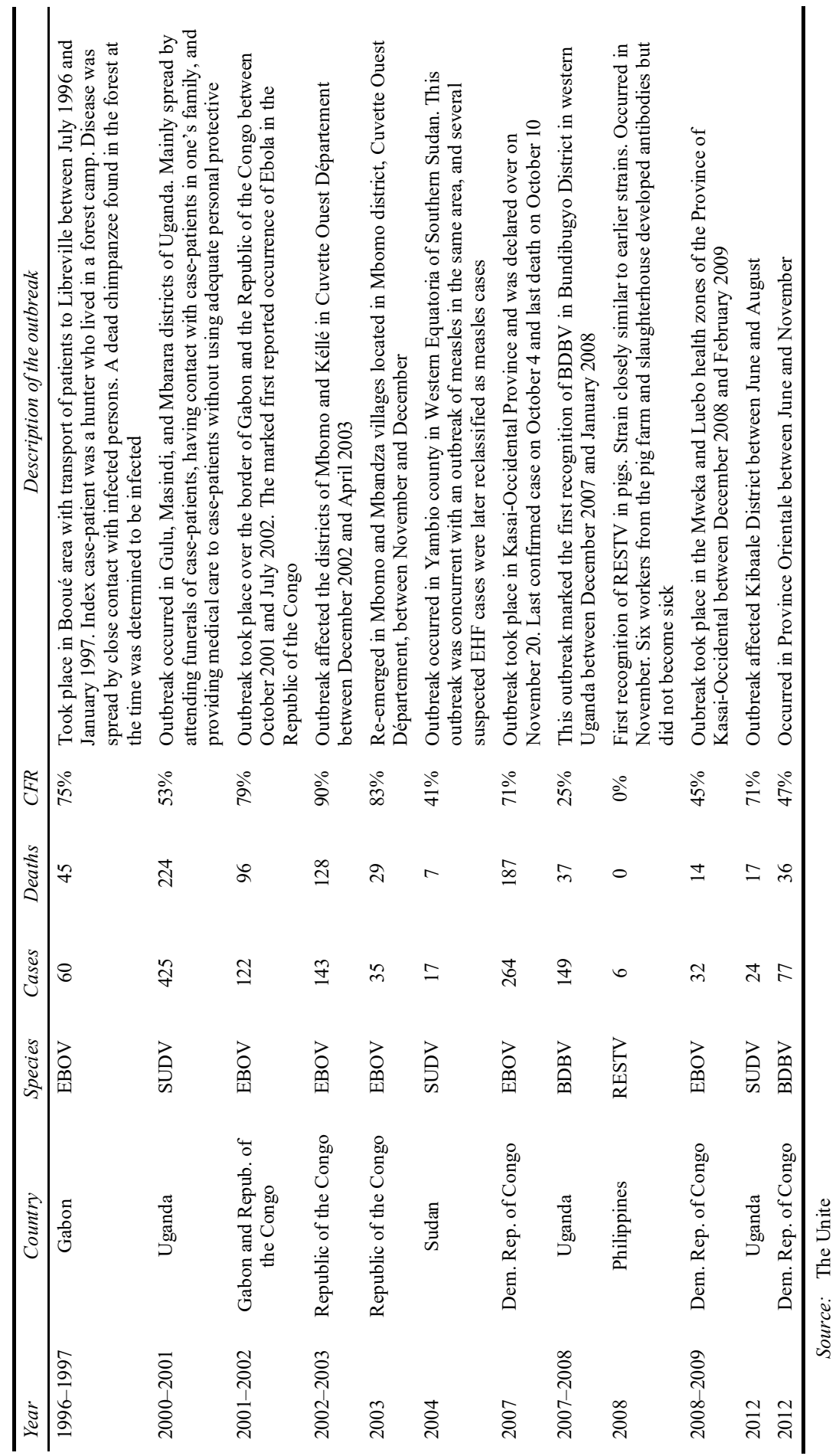

